\title{
PERLUKAH E-WALLET BERBASIS SYARIAH?
}

\author{
Ulin Nuha1, Moh. Nurul Qomar, ${ }^{2}$ Rafika Anissa Maulana ${ }^{3}$ \\ 1,2,3 Institut Agama Islam Negeri Kudus \\ $\triangle$ dzulvikri99@gmail.com
}

\begin{abstract}
: The purpose of this research is to find out about the transaction system in digital wallets (e-wallets) associated with the wadiah yad dhomanah contract in the study of muamalah fiqh. Whether the transaction is in accordance with the principles of Islamic finance so that it creates peace for Muslims in using the application.

Digital payments are currently a public need along with the development of information technology in particular. This is evidenced by the non-cash payment innovation. This innovation in Indonesia was formally carried out by Bank Indonesia through the National Non-Cash Movement (GNNT) in 2014. This movement aims to increase public awareness of the use of non-cash instruments so that a community that uses cashless instruments is gradually formed (cashless). society).

The technology cashless society clearly plays an important role in encouraging the consumption of Indonesia's middle class to be more consumptive. The presence of electronic money is one way to encourage people to become consumptive. The touch of technology in consumption through electronic money has provided a new color in interpreting consumption. Consumption does not only use its utility function to spend but also an identity function that needs to be fulfilled. Non-cash payment innovation in Indonesia continues to grow, along with the rise of financial technology (fintech) products in the form of digital wallets ( $e$-wallets) such as Go-Pay, OVO, Dana, LinkAja, Paytren, and so on.
\end{abstract}

Keywords $\quad$ : E-Wallet, Wadiah Contract, Transaction

\section{LATAR BELAKANG}

Literasi penggunaan electronic wallet (e-wallet) atau dalam bagasa indonesia disebut dompet digital sebagai media transaksi jual beli menjadi sebuah kebutuhan di tengah masa pendemi covid 19 sekarang ini. Hal ini dikarenakan masyarkat berusaha menghindari kontak fisik (physical distancing), termasuk dalam kegiatan jual beli sehingga transaksi mereka lebih sering menggunakan transaksi berbasis elektronik. Artinya kegiatan manusia terutama dalam bidang ekonomi sangat dipengaruhi oleh perkembangan teknologi. E-wallet sendiri adalah sebuah aplikasi yang memungkinkan para penggunanya untuk melakukan kegiatan jual beli secara online, biasanya penggunaannya pada aplikasi belanja online, atau aplikasi jasa lainnya.

Sebetulnya sejak tahun 2014, masyarakat didorong oleh BI untuk melakukan pembayaran non tunai. Secara formal, Bank Indonesia mempunyai program Gerakan Nasional Non Tunai (GNNT). Gerakan ini bertujuan meningkatkan kesadaran masyarakat terhadap penggunaan instrumen non tunai, sehingga berangsur-angsur 
terbentuk suatu masyarakat yang lebih menggunakan instrumen non tunai dalam ekonominya (cashless society). Dampak wabah covid 19 secara nyata pada penggunaan e-wallet adalah penggunaan aplikasi belanja online melonjak hingga 300 persen (Fatoni et al., 2019).

Cashless society sebenarnya sudah diprediksi oleh para pakar sejak debut pembayaran menggunakan kartu pada awal 1950-an. Setengah abad kemudian visi tersebut mulai terbukti. Apalagi banyak riset menemukan bahwa pergeseran menuju cashless society menguntungkan dan meningkatkan kesejahteraan ekonomi (GarciaSwartz, 2006). Meski demikian, transisi menuju cashless society akanmemerlukan serangkaian respons kebijakan untuk mengatasi pengaruh mata uang digital pada stabilitas keuangan dan efisiensi kebijakan moneter (Fabris, 2019).

Kendala kegiatan transaksi non tunai ada beberapa faktor, antara lain faktor sosial budaya serta faktor ketersediaan infrastruktur. Dalam hal ini antara pemerintah, pelaku usaha dan masyarakat masing-masing harus turut andil dalam mensosialisasikan cashless society (Tazkiyyaturrohmah, 2018).

Jati (2015) menjelaskan, dalam cashless society teknologi secara jelas berperan penting mendorong konsumsi kelas menengah Indonesia agar lebih konsumtif. Kehadiran uang elektronik menjadi salah satu cara mendorong masyarakat menjadi konsumtif. Adanya sentuhan teknologi dalam konsumsi melalui uang elektronik telah memberikan warna baru dalam memaknai konsumsi. Konsumsi tidak hanya menggunakan fungsi utilitasnya untuk dihabiskan, namun juga fungsi identitas yang perlu dipenuhi. Inovasi pembayaran non tunai di Indonesia terus berkembang, seiring maraknya produk financial technology (fintech) berupa dompet digital (ewallets) seperti Go-Pay,OVO,Dana,LinkAja,Paytren,dansebagainya.

Tumbuhnya dompet digital tersebut membuktikan bahwa inovasi fintech diterima masyarakat Indonesia. Bank Indonesia merilis penerbit uang elektronik resmi pada tahun 2020 berjumlah 51 perusahaan.

\begin{tabular}{|l|l|l|l|}
\hline No & Nama Perusahaan & No & Nama Perusahaan \\
\hline 1 & B.P.D. DKI JAKARTA & 26 & PT. ESPAY DEBIT INDONESIA KOE \\
\hline 2 & B.P.D. JABAR BANTEN & 27 & PT. EZEELINK INDONESIA \\
\hline 3 & B.P.D. SUMSEL BABEL & 28 & PT. FINNET INDONESIA \\
\hline 4 & BANK CENTRAL ASIA & 29 & PT. FINTEK KARYA NUSANTARA \\
\hline 5 & BANK CIMB NIAGA & 30 & PT. INDOSAT \\
\hline 6 & BANK MANDIRI (PERSERO) & 31 & PT. INTI DUNIA SUKSES \\
\hline 7 & BANK MEGA & 32 & PT. KERETA COMMUTER INDONESIA \\
\hline 8 & BANK NATIONALNOBU & 33 & PT. MASS RAPID TRANSIT JAKARTA \\
\hline 9 & $\begin{array}{l}\text { BANK NEGARA INDONESIA } \\
\text { 1946 (PERSERO) }\end{array}$ & 34 & $\begin{array}{l}\text { PT. } \\
\text { TECHNOLOGIES }\end{array}$ \\
\hline 10 & BANK OCBC NISP & 35 & PT. MNC TEKNOLOGI NUSANTARA \\
\hline 11 & BANK PERMATA & 36 & PT. NETZME KREASI INDONESIA \\
\hline
\end{tabular}




\begin{tabular}{|c|c|c|c|}
\hline 12 & BANK QNB INDONESIA & 37 & PT. NUSA SATU INTI ARTHA \\
\hline 13 & BANK RAKYAT INDONESIA & 38 & PT. PAPRIKA MULTI MEDIA \\
\hline 14 & BANK SINARMAS & 39 & $\begin{array}{lrrr}\text { PT. } & \text { RPAY } & \text { FINANSIAL } & \text { DIGITAL } \\
\text { INDONESIA } & & \\
\end{array}$ \\
\hline 15 & BNI SYARIAH & 40 & PT. SARANA PACTINDO \\
\hline 16 & $\begin{array}{l}\text { PT. AIRPAY INTERNASIONAL } \\
\text { INDONESIA }\end{array}$ & 41 & PT. SKYE SAB INDONESIA \\
\hline 17 & $\begin{array}{l}\text { PT. ARTAJASA PEMBAYARAN } \\
\text { ELEKTRONIS }\end{array}$ & 42 & PT. SMARTFREN TELECOM \\
\hline 18 & PT. ASTRA DIGITAL ARTHA & 43 & PT. SOLUSI PASTI INDONESIA \\
\hline 19 & PT. BIMASAKTI MULTI SINERGI & 44 & PT. TELEKOMUNIKASI INDONESIA \\
\hline 20 & $\begin{array}{l}\text { PT. BLUEPAY } \\
\text { INTERNASIONAL }\end{array}$ & 45 & PT. TELEKOMUNIKASI SELULAR \\
\hline 21 & $\begin{array}{lll}\text { PT. } & \text { BUANA } & \text { MEDIA } \\
\text { TEKNOLOGI } & \end{array}$ & 46 & PT. TRANSAKSI ARTHA GEMILANG \\
\hline 22 & $\begin{array}{lcl}\text { PT. } & \text { CAKRA } & \text { ULTIMA } \\
\text { SEJAHTERA } & \end{array}$ & 47 & $\begin{array}{lll}\text { PT. } & \text { VERITRA } & \text { SENTOSA } \\
\text { INTERNASIONAL } & \\
\end{array}$ \\
\hline 23 & PT. DATACELL INFOMEDIA & 48 & PT. VISI JAYA INDONESIA \\
\hline 24 & PT. DOMPET ANAK BANGSA & 49 & PT. VISIONET INTERNASIONAL \\
\hline \multirow[t]{2}{*}{25} & PT. E2PAY GLOBAL UTAMA & 50 & PT. WITAMI TUNAI MANDIRI \\
\hline & & 51 & PT. XL AXIATA \\
\hline
\end{tabular}

Sumber;https://www.bi.go.id/id/statistik/sistem-pembayaran/uang elektronik/contents/penyelenggara\%20uang\%20elektronik.aspx

Merujuk data di atas, penerbit uang elektronik syariah masih sangat terbatas, padahal kebutuhan transaksi online semakin maningkat. Hal yang lebih prinsip lagi apakah keberadaan e-wallet syariah urgen untuk dihadirkan.

\section{TEORI DAN METODE}

\subsection{Penelitian Terdahulu}

Pertama, Analisis Penggunaan Dompet Elektronik (e-wallet) sebagai Alat Transaksi (e-Money) dalam Perspektif Maqașid As-Syarı̄'ah menemukan bagaimana kesesuaian uang elektronik dengan Maqașid Syarīah. Apakah uang elektonik tersebut telah sesuai dengan syariat Islam atau tidak. Kesesuaian ini didapat dengan terpenuhinya prinsip memelihara harta dan kemaslahatan (Muamar \& Alparisi, 2017). 
Kedua, Irfan Nurfalah, Aam Slamet Rusdiyana, dalam jurnal yang berjudul "Digitalisasi Keuangan Syariah menuju Keuangan Inklusif: Kerangka Maqașid Syarī'ah" menemukan bagaimana kesesuaian antara inovasi teknologi dalam produk dan layanan keuangan syariah dengan tataran pedoman kebutuhan-kebutahan saat ini yang sesuai dengan syariat. Kesesuaian ini didapat dengan konsep Maqașid Syarı̄'ah yaitu dapat membantu meningkatkan tingkat literasi dan inklusi keuangan syariah serta mendukung kebutuhan halal sesuai Maqașid Syarīah (Nurfalah \& Rusydiana, 2019).

Ketiga, A Mulyana, H Wijaya, dalam jurnal yang berjudul "Perancangan EPayment System pada E-Wallet Menggunakan Kode QR Berbasis Android" menemukan bagaimana membuat E-payment System yang dapat memberikan kemudahan bertransaksi dengan memiliki 3 metode yaitu menggunakan Sidik Jari, RFID dan QR Code serta pengelolaan keuangan menggunakan aplikasi Android (Mulyana \& Wijaya, 2018).

Keempat, Agus Agung Sosilo, dalam Skripsi yang berjudul, "Transaksi Go-Pay pada Perusahaan Ojek Online Perbandingan Akad Qardh dan Wadi'ah" menemukan bagaimana penggunaan transaksi Go-Pay pada aplikasi online Go-Jek dengan akad qardh. Sementara permasalahan go-pay jika itu qardh, berarti pihak customer tidak boleh menerima keuntungan apapun dari pihak gojek. Akan tetapi go-jek memberikan diskon bagi mereka yang membayar via go-pay. Konsekuensi dari akad qardh maka dalam kasus go-pay bahwa khusus pengguna jasa go-pay yang membayar jasa dengan gopay mendapat potongan harga maka ini adalah manfaat yang diberikan muqtaridh (penerima pinjaman) kepada muqridh (memberi pinjaman) dan setiap pinjaman yang mendatangkan manfaat bagi pemberi pinjaman hukumnya adalah Riba. Akad Topup lebih tepat disebut sebagai akad wadi'ah (titipan) dibandingkan dengan akad hutang (qardhum) karena ciri khas dari wadi'ah (titipan) adalah barang titipan bisa diambil sewaktu-waktu dan jangka waktu penitipannya tidak harus disebutkan. Sedangkan ciri khas hutang adalah ada jangka waktu tempo berhutangnya (Susilo, 2018).

Dan kelima, Rifqy Tazkiyatul Rohmah, dalam tesis yang berjudul "Transaksi Uang Elektronik Ditinjau dari Hukum Bisnis Syariah" menemukan bagaimana uang elektronik yang ditinjau dari hukum bisnis Islam. Dan bagaimana pengaruh penggunaan dari uang elektronik Registered dan penggunaan uang elektronik Unregistered dalam kehidupan masyarakat jika dilihat dari teori uang dan teori hifz al mal yang ada dalam kajian hukum Islam (Rohmah, 2016).

\subsection{Pengertian Financial Technology (Fintech)}

Financial Technology (Fintech) merupakan pengunaan teknologi untuk dapat memberikan solusi solusi keuangan (Arner, et al, 2015). Fintech juga dapat didefinisikan sebagai inovasi teknologi dalam layanan keuangan yang dapat menghasilkan model bisnis, aplikasi, proses atau produk-produk dengan efek 
material yang terkait dengan penyediaan layanan keuangan. Implemetasi hal tersebut diusulkan membuat akun pada aplikasi Bebas Bayar dan mengajak warga sekitar masjid untuk menggunakan aplikasi fintech tersebut bertujuan agar masjid memiliki alternatif sumber pendapatan (Wisandiko, Firman Adhar Indarwati, 2020). Artinya penggunaan fintech tidak mengenal syariah atau tidak, namun sistem fintech tersebut yang mepengaruhi hukum islam dari fintech itu sendiri.

\subsection{Pengertian E-Wallet}

E-Wallet atau dompet elektronik adalah alat pembayaran digital atau alat pembayaran digital yang menggunakan media elektronik berupa server based. Pada umumnya e-Wallet berupa aplikasi yang berbasis di server dan dalam proses pemakaiannya memerlukan sebuah koneksi terlebih dulu dengan penerbitnya (Mulyana \& Wijaya, 2018). E-wallet sendiri bertujuan mempermudah transaksi dan merupakan dari fintech.

\subsection{Metode Penelitian}

Jenis penelitian yang digunakan adalah penelitian kualitatif dengan pendekatan library research. Data primer didapatkan dari artikel ilmiah terupdate dirangkum dengan beberapa informasi dari we-web terpercaya. Adapun data sekunder yang digunakan di sini yaitu, skripsi, jurnal, dan website yang berkaitan dengan system akad wadiah dalam fiqih muamalah, dan dompet elektronik.

\section{HASIL DAN PEMBAHASAN}

\subsection{Gambaran Dompet E-Wallet}

E-Wallet atau Dompet elektronik memungkinkan para pengguna untuk melakukan transaksi jual-beli elektronik secara cepat dan aman. Dompet elektronik berfungsi hampir sama dengan dompet saku. Dompet elektronik pertama kalinya diakui sebagai sebuah metode untuk menyimpan uang dalam bentuk elektronik, namun kemudian menjadi populer karena cocok untuk menyediakan cara yang nyaman bagi pengguna Internet untuk menyimpan dan menggunakan informasi berbelanja secara daring (online). Berdasarkan Peraturan Bank Indonesia, Dompet Elektronik merupakan layanan elektronik untuk menyimpan data instrumen pembayaran antara lain alat pembayaran dengan menggunakan kartu dan/atau uang elektronik, yang dapat juga menampung dana, untuk melakukan pembayaran.

Dengan perkembangan dunia internet yang semakin maju mendorong penggunaan dompet elektronik sebagai alat transaksi yang lebih efisien ketimbang menggunakan bank. ini terbukti dengan banyaknya website dan aplikasi e-commerce yang menggunakan dompet elektronik sebagai alat transaksinya. Ada beberapa layanan dompet elektronik yang kini banyak digunakan dalam transaksi online diantaranya ialah Gopay, Ovo dan Dana yang merupakan dompet elektronik yang paling banyak digunakan dalam transaksi online di Indonesia. 
Dompet elektronik terdiri dari komponen perangkat lunak dan informasi. Perangkat lunak menyediakan keamanan dan penyandi keamanan (encryption) untuk informasi pribadi dan transaksi itu sendiri. Biasanya, dompet elektronik disimpan oleh klien sebagai pengguna dan dapat dikelola secara mudah serta terafiliasi dengan banyak situs dan aplikasi niaga.

Dompet elektronik yang disimpan di sisi peladen (server), juga dikenal sebagai "dompet tipis", yang merupakan suatu aplikasi yang dibuat oleh perusahaanperusahaan yang dikelola di peladen mereka. Dompet elektronik sisi peladen populer di antara para pedagang karena keamanan dan dayagunanya (efficiency).

Komponen informasi untuk dompet macam ini pada dasarnya berbentuk menyerupai pangkalan data dari informasi yang dimasukkan oleh pengguna. Informasi tersebut terdiri dari alamat pengiriman, alamat penagihan, cara pembayaran (termasuk nomor kartu kredit, tanggal jatuh tempo, dan nomor keamanan), dan informasi lainnya.

Sebuah dompet elektronik sisi klien pada umumnya mudah untuk digunakan. Setelah perangkat lunak tersebut terpasang, pengguna dapat mulai memasukkan semua informasi yang tepat. Sewaktu pembayaran/lapor-keluar (check-out) di halaman situs e-niaga, peranti lunak dompet elektronik tersebut dapat secara otomatis memasukkan informasi pengguna pada formulir daring. Secara asali (default), kebanyakan perangkat lunak dompet elektronik meminta pengguna untuk memasukkan sandi sebelum mengisi formulir tersebut. Langkah ini menjaga pengguna yang tidak sah agar tidak dapat melihat informasi pribadi yang disimpan di komputer tersebut.

Dompet elektronik sisi peladen tidak perlu dipasang di komputer. Pengguna hanya perlu mengunjungi situs yang menyediakan layanan tersebut, lalu melakukan pendaftaran dan mengikuti langkah-langkah yang diperintahkan situs tersebut.

\subsection{Dompet Digital dalam Islam}

Dompet digital merupakan sesuatu hal yang baru dalam system pembayaran. Dalam pandangan islam khususnya bidang muamalat memegang prinsip " pada dasarnya dalam hal muamalat semuanya itu diperbolehkan kecuali ada dalil yang melarangnya ". Oleh karena itu wajar-wajar saja kalo islam memandang suatu perubahan sebagai sunnatullah.

Buya yahya seorang ulama kharismatik memberikan pendapat yang berhubungan dengan dompet digital, diantaranya : "Kalau niat kita untuk membayar jasa, maka secara sah kita halal. Karena mereka mempunyai kesepakatan, dan tidak ada riba disini. Gambaran sederhana saat kita membayar kebutuhan kita dulu, melalui sistem ada yang motong saldo. Dan diberikan kepada pemberi jasa itu sah-sah saja tidak riba"

Sehingga pada intinya hukum dari dompet digital adalah diperbolehkan karena sebenarnya adanya dompet digital itu untuk mempermudah. Pembayaran menggunakan digital sendiri juga untuk membayar jasa yang telah mereka berikan kepada konsumen. Perihal haram dan tidaknya suatu dompet digital sebenarnya kembali lagi pada para pengguna dompet digital itu sendiri. Biasanya dari pihak online telah memberikan syarat dan ketentuan sebagai informasi kesepakatan dengan konsumen dan itu perlu persetujuan.

Trend yang saat ini berkembang inilah yang terkadang menjadi kegelisahan bagi masyarakat. Namun sebagai umat islam kembali lagi ke akad. Dan memahami nilainilai riba. Untuk itu alangkah baiknya pengguna dompet digital memahami dan 
membaca betul mengenai persetujuan syarat dan ketentuan menggunakan dompet digital. Agar tidak terjadi kesalah pahaman terkait hal tersebut. Sementara dari pihak perusahaan sendiri juga sudah berusaha untuk memudahkan konsumen dalam pembayaran bila dompet tertinggal, lupa tidak membawa uang cash maka bisa menggunakan dompet digital.

Dapat diambil kesimpulan bahwa Hukum dompet digital dalam Islam adalah diperbolehkan dan sah-sah saja. Apalagi dompet digital sebenarnya juga untuk mempermudah masyarakat untuk bertransaksi ketika tidak membawa uang tunai. Namun tetap memperhatikan syariat islam ketika menggunakannya. 


\section{PENUTUP}

Dari sudut pandang keuangan syariah, system transaksi yang berlaku dalam dompet digital masuk dalam kategori akad wadiah yad dhomanah disebabkan terpenuhinya syarat dan rukunnya. Oleh karena itu, keraguan umat islam tentang uang digital harus mulai di tepis. Dalam pandangan syariah uang hanya sebatas alat tukar bukan capital . bukankah dalam pandangan maqasid syariah, kemaslahatan merupakan yang utama. Dari uraian di atas, dapat diambil dua kesimpulan, yaitu pertama, penggunaan dompet elektronik (e-wallet) sebagai Alat Transaksi merupakan sebuah alat pembayaran yang Syah, sesuai Peraturan Bank Indonesia (PBI) Nomor18/40/2016 tentang Penyelenggaraan Pemrosesan Transaksi Pembayaran dompet elektronik $(e-$ wallet) merupakan layanan elektronik untuk menyimpan data instrument pembayaran antara lain alat pembayaran dengan menggunakan kartu dan/atau uang elektronik, yang dapat juga menampung dana, untuk melakukan pembayaran. Keberadaan Dompet Digital memberikan banyak kemudahan dalam bertransaksi disetiap merchant rekanannya, seperti halnya mempermudah transaksi, tidak repot membawa uang tunai. Dan kedua, kedudukan sistem transaksi dompet elektronik (ewallet) menurut pandangan teori keuangan syariah adalah halal dan tidak dapat diragukan lagi. Karena dompet elektronik (e-wallet) terhindar dari hal-halyang dilarang oleh Syariat, diselenggarakan dengan akad yang jelas. Sehingga kesesuaian dompet elektronik ( $e$-wallet) sesuai dengan prinsip memelihara harta (hifdzul Mal) terjaga dengan baik. Kemudian dompet elektronik ( $e$-wallet) sudah dilindungi dengan keamanan yang baik seperti adanya Security Code pada aplikasi OVO yaitu berupa PIN yang terdiri dari 6 (enam) digit angka layaknya security code pada ATM. Kode rahasia ini dapat pengguna ganti kapanpun tanpa batasan kali perubahan. Ini menjelaskan bahwa dompet elektronik ( $e$-wallet) telah sesuai dengan Maqa>șid Syari'ah. Secara keseluruhan dompet elektronik ( $e$-wallet) telah sesuai dengan prinsip akad wadiah yad amanah. 


\section{DAFTAR PUSTAKA}

Bakri, A. J. (1996). Konsep Maqashid Syari'ah Menurut Al-Syatibi. Jakarta:PT. Raja Grafindo Persada.

Danin, S. (2002). Menjadi Penelitian Kualitatif. Bandung: Pustaka Setia.

Effendi, S. (2009). Ushul Fiqh, cetakan ke3.Jakarta Kencana Prenada MediaGroup.

Firmansyah, M. A. (2018). Perilaku Konsumen (Sikap dan Pemasaran).Yogyakarta:Deepublish.

Ghazaly, A. R.,et al. (2010). Fiqh Muamalat. Jakarta: Kencana Prenada Media Group, 2010. Hariyani, I., Serfiyani, C. Y., \& Purnomo, R.S. D. (2018). Penyelesaian Sengketa Bisnis. Jakarta: Gramedia Pustaka Utama.

Moleong, L. J. (2014). Metodologi Penelitian Kualitatif. Bandung: PT. RemajaRosdakarya. 104

Muamar, A., \& Alparisi, A. S. (2017). Electronic money (e-money) in maqashid al-sharia perspective. Journal of Islamic Economics Lariba, 3(2), 75-84.

Mulyana, A., \& Wijaya, H. (2018).Perancangan E-Payment System pada E-Wallet Menggunakan Kode QR Berbasis Android. Komputika: Jurnal Sistem Komputer, $7(2), 63-69$

Muzaki, S. (2018). Analisis fatwa MUI No.116/DSN-MUI/IX/2017 dan PBI No.20/6/PBI/2018 Tentang Uang Elektronik Syariah ditinjau dari perspektif maqasid asy syari'ah (Bachelor's thesis, Fakultas Syariah dan Hukum Universitas Islam Negeri Syarif Hidayatullah Jakarta).

Narbuko, C. \& Achmadi, A. 2009. MetodePenelitian. Jakarta: PT. Bumi Aksara.

Nurfalah, I., \& Rusydiana, A. S. (2019). Digitalisasi keuangan syariah menuju keuangan inklusif: Kerangka maqashidsyariah. Ekspansi: Jurnal Ekonomi,Keuangan, Perbankan dan Akuntansi, 11(1), 55-76.

Peraturan Bank Indonesia (PBI) Nomor 18/40/2016 tentang Penyelenggaraan Pemrosesan TransaksiPembayaran.https://www.bi.go.id/id/peraturan/sistempembayaran/Page s/pbi_184016.aspx

Pratama, B. (2017). Terminologi Hukum Uang Digital dan Dompet Digital. https://businesslaw.binus.ac.id/2017/09/30/mengenaluang-digital-dan-dompetdigital/

Rahmawati. (2013). Maqashid Al-Syari'ah Dalam Ekonomi Islam Muamalah. Jurnal Ekonomi, 3(2), 94. 
Rohmah, T.T. (2016). Transaksi Uang Elektronik Di Tinjau dari Hukum Bisnis Syariah (Tesis, PascasarjanaUIN Sunan Kalijaga).

Rukajat, A. (2018). Pendekatan Penelitian Kualitatif (Qualitative ResearchApproach). Yogyakarta: Deepublish.

Sahrani, S. \& Abdullah, R. (2011). Fikih Muamalah, Ghalia Indonesia, Bogor.

Sarwono, J., \& Prihartono, K. (2012). Perdagangan online: cara bisnis diinternet. Jakarta: PT Elex Media Komputindo.

Sugiyono.(2013). Metode Penelitian Kombinasi (Mixed Methods). Bandung: Alfabeta Susilo, A. A. (2018). Transaksi Go-Pay pada perusahaan Ojek Online perbandingan Akad Qardh dan Wadi'ah (Skripsi,Universitas Islam Negeri Maulana Malik Ibrahim).

Arner, D. W., Barberis, J., \& Buckley, R. P. (2015). The Evolution of FinTech: A New PostCrisis Paradigm? 1-54. 